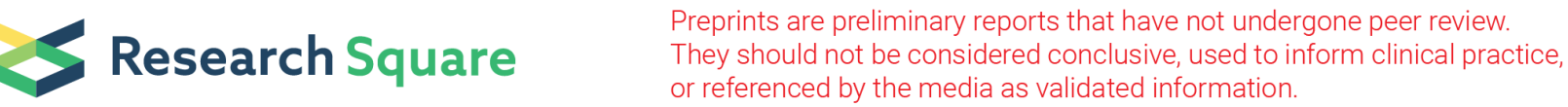

\section{Application of Indocyanine Green Videoangiography in Cerebellar Hemangioblastoma Surgery as a Valuable Adjunctive Surgical Tool}

Joonho Byun ( $\nabla$ drjunho2@gmail.com )

Asan Medical Center https://orcid.org/0000-0003-0687-3286

Moinay Kim

Asan Medical Center

Sang Woo Song

Asan Medical Center

Young-Hoon Kim

Asan Medical Center

Chang Ki Hong

Asan Medical Center

Jeong Hoon Kim

asan medical center

\section{Research Article}

Keywords: hemangioblastoma, indocyanine green, surgery, videoangiography

Posted Date: October 18th, 2021

DOl: https://doi.org/10.21203/rs.3.rs-970242/v1

License: (c) (i) This work is licensed under a Creative Commons Attribution 4.0 International License. Read Full License 


\section{Abstract \\ Introduction}

: Surgery for cerebellar hemangioblastoma can be challenging because of the tumor's location in the posterior fossa and its inherent nature of hypervascularity.

\section{Methods}

We reviewed a total of seven consecutive patients who received microsurgery adjunction with indocyanine green (ICG) videoangiography.

\section{Results}

Our study included four female and three male patients. All tumors were located in the cerebellum. We used ICG videoangiography for the purposes of identifying a small tumor inside the cyst in one case, for defining feeding arteries and draining veins in three cases, for confirming residual tumor in the resection cavity in two cases, and for assessment of tumor shunt flow in one case of extremely hypervascular hemangioblastoma. Median blood loss during surgery was $100 \mathrm{~mL}$, and total resection was achieved in all cases with no complications. No adverse effects of ICG videoangiography were observed.

\section{Conclusions}

ICG videoangiography is a very useful adjunctive tool for cerebellar hemangioblastoma surgery.

\section{Introduction}

Hemangioblastoma (HGB) of the central nervous system are known as hypervascular benign tumors [1]. HGB frequently accompany tumor cysts around the solid nodule[1, 2] (Ref: acta). For cystic tumors, the cystic cavity can be opened during tumor resection. However, identifying small nodules in the cystic cavity can be challenging [2, 3]. Solid HGB show characteristics of arteriovenous malformation, internal decompression, or piecemeal resection, and harbor the risk of potentially devastating intraoperative bleeding or swelling [4, 5]. Indocyanine green (ICG) is widely used for visualizing the flow in vessels in cerebrovascular surgery [6]. Some surgeons also use ICG for brain tumor surgery [5, 7]. In this study, we report the application of ICG angiography during cerebellar HGB surgery.

\section{Materials And Methods}

Patient enrollment

The study protocol and review of medical records were approved by the institutional review board of Asan Medical Center, University of Ulsan College of Medicine, Seoul, Korea. Between January 2020 and July 2021, seven patients with a diagnosis of cerebellar HGB were treated with microsurgical resection in our institution. All microsurgeries were performed by two neurosurgeons (JB, CKH), and ICG videoangiography was used as an adjunctive tool integrated into the surgical microscope. 


\section{Microscope And Indocyanine Green Angiography}

We used an OPMI Pentero and Kinevo surgical microscope (Carl Zeiss, Co., Oberkochen, Germany) integrated with ICG videoangiography. In each procedure, ICG (8e12.5 mg) was injected into the internal jugular vein as a bolus by the anesthesiologist. Arterial, capillary, and venous angiographic images could be observed on the video screen in real time. Surgical videos were recorded and reviewed immediately for analysis.

\section{Results}

Our study included four female and three male patients. All HGB tumors were located in the cerebellum. Midline suboccipital craniotomy and lateral suboccipital craniotomy were performed for tumor resection. All tumors were resected totally. Estimated blood loss was minimal and the blood loss in five of seven patients was less than $100 \mathrm{~mL}$ There were no postoperative complications. Detailed characteristics of the enrolled patients are presented in Table 1.

Table 1

Details of the enrolled patients

\begin{tabular}{|c|c|c|c|c|c|c|c|c|}
\hline $\begin{array}{l}\text { Case } \\
\text { No. }\end{array}$ & Sex/Age & Location & $\begin{array}{l}\text { Tumor } \\
\text { type }\end{array}$ & $\begin{array}{l}\text { Surgical } \\
\text { approach }\end{array}$ & $\begin{array}{l}\text { Purposes of ICG } \\
\text { videoangiography }\end{array}$ & $\begin{array}{l}\text { Extent of } \\
\text { resection }\end{array}$ & $\begin{array}{l}\text { Blood } \\
\text { loss } \\
\text { during } \\
\text { surgery }\end{array}$ & $\begin{array}{l}\text { Immediate } \\
\text { postoperative } \\
\text { complication }\end{array}$ \\
\hline 1 & $F / 54$ & Cerebellum & $\begin{array}{l}\text { Solid } \\
+ \\
\text { cystic }\end{array}$ & $\begin{array}{l}\text { Midline } \\
\text { SOC }\end{array}$ & $\begin{array}{l}\text { Identifying small } \\
\text { tumor }\end{array}$ & GTR & $\begin{array}{l}<100 \\
\mathrm{~mL}\end{array}$ & None \\
\hline 2 & $\mathrm{~F} / 75$ & Cerebellum & $\begin{array}{l}\text { Solid } \\
+ \\
\text { cystic }\end{array}$ & $\begin{array}{l}\text { Lateral } \\
\text { SOC }\end{array}$ & $\begin{array}{l}\text { Defining feeding } \\
\text { arteries and } \\
\text { draining veins }\end{array}$ & GTR & $\begin{array}{l}<100 \\
\mathrm{~mL}\end{array}$ & None \\
\hline 3 & $\mathrm{M} / 50$ & Cerebellum & Solid & $\begin{array}{l}\text { Lateral } \\
\text { SOC }\end{array}$ & $\begin{array}{l}\text { Confirming } \\
\text { residual tumor }\end{array}$ & GTR & $\begin{array}{l}100- \\
200 \\
\mathrm{~mL}\end{array}$ & None \\
\hline 4 & $M / 48$ & Cerebellum & $\begin{array}{l}\text { Solid } \\
+ \\
\text { cystic }\end{array}$ & $\begin{array}{l}\text { Lateral } \\
\text { SOC }\end{array}$ & $\begin{array}{l}\text { - Identifying small } \\
\text { nodules } \\
\text { - Defining feeding } \\
\text { arteries and } \\
\text { draining veins }\end{array}$ & GTR & $\begin{array}{l}<100 \\
\mathrm{~mL}\end{array}$ & None \\
\hline 5 & $\mathrm{~F} / 80$ & Cerebellum & Solid & $\begin{array}{l}\text { Lateral } \\
\text { SOC }\end{array}$ & $\begin{array}{l}\text { Confirming } \\
\text { residual tumor }\end{array}$ & GTR & $\begin{array}{l}<100 \\
\mathrm{~mL}\end{array}$ & None \\
\hline 6 & $F / 59$ & Cerebellum & $\begin{array}{l}\text { Solid } \\
+ \\
\text { cystic }\end{array}$ & $\begin{array}{l}\text { Midline } \\
\text { SOC }\end{array}$ & $\begin{array}{l}\text { Determining } \\
\text { tumor location }\end{array}$ & GTR & $\begin{array}{l}<100 \\
\mathrm{~mL}\end{array}$ & None \\
\hline 7 & $M / 18$ & Cerebellum & Solid & $\begin{array}{l}\text { Midline } \\
\text { SOC }\end{array}$ & $\begin{array}{l}\text { - Defining feeding } \\
\text { arteries and } \\
\text { draining veins } \\
\text { - Assessing } \\
\text { arteriovenous } \\
\text { shunt flow }\end{array}$ & GTR & $\begin{array}{l}500 \\
\mathrm{~mL}\end{array}$ & None \\
\hline
\end{tabular}

Illustrated cases 


\section{Case 1}

A 54-year-old female patient visited the clinic because of dysmetria. Magnetic resonance imaging (MRI) showed a cystic mass with a mural nodule in the left cerebellum. Microsurgical resection was performed via midline suboccipital craniotomy. After opening the cyst wall, the mural nodule was explored. ICG angiography was performed to identify the small nodule. It was totally resected (Figure 1-A).

\section{Case 2}

A 59-year-old female patient visited the clinic because of an incidental finding of a cerebellar tumor after minor head trauma. MRI showed solid hypervascularity in the right cerebellum. Microsurgical resection was performed via midline suboccipital craniotomy. The tumor was located subcortically, thus ICG angiography was performed to localize the tumor. The brightly stained tumor was localized and totally resected without complication (Figure 1-B).

\section{Case 3}

An 18-year-old male patient visited the clinic because of pulsatile tinnitus. A large arteriovenous malformation resembling a tumor was found in a brain MRI. Large tumor-draining veins to the tentorial sinus were found. During tumor resection, tumor shunt flow was assessed using ICG angiography to prevent devastating bleeding in case the vein was inadvertently injured during resection. The tumor was totally resected without immediate complication. However, delayed hemorrhage occurred on postoperative day \#14 (Figure 2-A).

\section{Case 4}

A 49-year-old male patient visited the clinic because of headache. A solid tumor with a cyst was located in the right cerebellum. Because of his religious background as a Jehovah's witness, he denied blood transfusion during surgery. ICG angiography was performed to identify feeding arteries and veins to minimize blood loss. The tumor was totally resected without complication. Blood loss during surgery was less than $100 \mathrm{~mL}$ (Figure 2-B).

\section{Discussion}

Understanding the hemodynamics and angioarchitecture is essential in HGB surgery. HGB are characterized by tumor hypervascularity. Thus, surgical resection harbors the risk of significant blood loss and surgical complications $[1,8,9]$. Conventional angiography, computed tomography angiography, or magnetic resonance angiography are usually performed to evaluate the angioarchitecture of HGB [2]. However, real-time vascular imaging is more helpful during tumor resection. Doppler ultrasonography (US) has been used for distinguishing arteries and veins of tumors. Doppler US has also the advantage of being non-invasive and straightforward to apply for evaluating vessels. However, Doppler US is less reliable for small arteries and low-flow tumor vessels and it cannot visualize tumors, vessels, and the direction of blood flow. Since recently, ICG angiography is widely used in cerebrovascular surgery [6], and it may also have potential for brain tumor surgery. The results of ICG angiography are easy to interpret to determine the angioarchitecture of HGB tumors. In addition, ICG infusion is a safe procedure and can be performed repeatedly. Kim et al. reported various applications of ICG angiography for brain tumor surgery [7] and shared their experience using ICG angiography for various types of brain tumors. HGB tumors show bright staining in ICG angiography [5, 7]. Moreover, ICG angiography can reveal the feeding arteries, draining veins, and the direction of flow. Thus, ICG angiography is a more useful adjunctive tool than Doppler US in HGB resection.

The morphology of HGB is heterogeneous and HGB are frequently accompanied by tumor cysts, making tumor resection potentially challenging. Identifying small mural nodules in the large cyst is difficult via gross microscopic 
inspection but is easy via the ICG microscopy mode. In addition, using bright tumor staining by ICG may be used to confirm the total resection of HGB tumors.

Assessing feeding arteries and draining veins is important in HGB surgery because coagulation of feeding arteries reduces bleeding during surgery. Minimizing blood loss can reduce the need for blood transfusion, helps with rapid recovery of patients, and overall reduces the cost of hospitalization. In addition, because ICG fluorescence can penetrate the dura mater, ICG is useful to assess cortical vessels and trans-dural feeders before dura opening [7].

Large solid HGB tumors can mimic arteriovenous malformation, showing numerous feeding arteries and large draining veins $[9,10]$. These large tumors can harbor tumor-related arteriovenous shunts. Premature occlusion of shunts without adequate feeding arteries causes devastating bleeding which can put the entire surgical procedure at risk. ICG angiography is useful for assessing shunt flow and direction of blood flow, and can help identifying the residual feeders after subcortical dissection of the tumor.

In our experience, ICG angiography is very useful during HGB surgery. The purposes of ICG angiography are listed below.

$<$ The purposes of ICG angiography>

- Identifying small tumors inside of tumor cysts

- Identifying tumors that are located in subcortical areas

- Defining feeding arteries and draining veins

- Confirming extent of resection, residual tumor tissue

- Assessing tumor-related arteriovenous shunt flow

The limitation of ICG angiography is that it is available only for vessels visible in the operative field. It cannot visualize vessels and tumors which are covered with brain parenchyma. Weak staining of tumor tissue just beneath the cortex and dura mater could be seen but deeper-seated tumors could not be visualized. Although the incidence is extremely low, anaphylactic reactions such as itching sensation, skin eruption, arrhythmia, and hypotension have been reported after ICG administration [11]. These side effects should be discussed preoperatively.

\section{Conclusion}

ICG videoangiography is a very useful adjunctive tool for cerebellar HGB surgery. ICG angiography has the potential to be applied for various purposes during HGB resection. Furthermore, ICG angiography is relatively safe and may be an alternative to intraoperative catheter angiography or Doppler US.

\section{Declarations}

The authors declare no competing interests regarding this study.

\section{Funding}

This research did not receive any specific grant from funding agencies in the public, commercial, or not-for-profit sectors.

\section{Availability of data and material}

The data supporting the findings of this study are included in the article and its supplementary material file. 


\section{Authors' contributions}

Author contributions JB conceived and designed the study. YHK, SWS and CKH conducted the literature search. JB, YHK, SWS and CKH were involved in the analysis and interpretation of data. JB drafted the manuscript. The study was supervised by $\mathrm{CKH}$ and JHK. All authors read and approved the final manuscript.

\section{Ethics approval}

This retrospective study has been approved by the appropriate ethics committee and was performed in accordance with the ethical standards laid down in the 1964 Declaration of Helsinki and its later amendments. (Approval by IRB of Asan Medical Center, No. 2021-1139-0001). The IRB of Asan Medical Center gave the right of exemption of 'informed consent' for this study. The reason described below.

The risk expected from this 'retrospective observational study' is not greater than the Level I risk. In addition, all of included patients' dataset were anonymized. There is no reason to presume the refusal of the research subject's consent, and the risk to the enrolled patients is extremely low even if consent is waived. Consent exemption does not infringe on the rights or welfare of the subject. It is not the research for drug/medical device approval, and it is not a research regulated by a foreign regulatory agency.

\section{Acknowledgments}

The authors thank Se Hee Kim, a statistician in our institute, who performed the statistical analysis and assisted in the writing of the Methods section of this report. We also thank Minji Rickie Kim, a neurologists of WECANDO Clinic, who gave us warm advice and help.

\section{References}

1. Silver ML, Hennigar G (1952) Cerebellar Hemangioma (Hemangioblastoma). J Neurosurg:484-494. doi:https://doi.org/10.3171/jns.1952.9.5.0484

2. Kim EH, Moon JH, Kang S-G, Lee KS, Chang JH (2020) Diagnostic challenges of posterior fossa hemangioblastomas: Refining current radiological classification scheme. Sci Rep 10:267. doi:https://doi.org/10.1038/s41598-020-63207-0

3. Suh CH, Kim HS, Kim JH, Kim SJ (2020) Cerebellar Hemangioblastoma: Diagnostic Yield of Contrast-Enhanced Abdominal CT and Whole-Spine MRI as Initial Screening Imaging. Am J Roentgenol 215:706-712. doi:doi.org/10.2214/AJR.19.22447

4. Cui H, Zou J, Bao YH, Wang MS, Wang Y (2017) Surgical treatment of solid hemangioblastomas of the posterior fossa: A report of 28 cases. Oncology Letters 13:1125-1130. DOI:10.3892/ol.2016.5531 doi

5. Hojo M, Arakawa Y, Funaki T, Yoshida K, Kikuchi T, Takagi Y, Araki Y, Ishii A, Kunieda T, Takahashi JC, Miyamoto S (2014) Usefulness of Tumor Blood Flow Imaging by Intraoperative Indocyanine Green Videoangiography in Hemangioblastoma Surgery. World Neurosurgery 82:e495-e501. doi:http://dx.doi.org/10.1016/j.wneu.2013.02.009

6. Hardesty DA, Thind H, Zabramski JM, Spetzler RF, Nakaji P (2014) Safety, efficacy, and cost of intraoperative indocyanine green angiography compared to intraoperative catheter angiography in cerebral aneurysm surgery. Journal of Clinical Neuroscience 21:1377-1382. doi:http://dx.doi.org/10.1016/j.jocn.2014.02.006

7. Kim EH, Cho JM, Chang JH, Kim SH, Lee KS (2011) Application of intraoperative indocyanine green videoangiography to brain tumor surgery. Acta Neurochir 153:1487-1495. DOI 10.1007/s00701-011-1046-x doi

8. Cheng J, Liu W, Zhang S, Lei D, Hui X (2017) Clinical Features and Surgical Outcomes in Patients with Cerebellopontine Angle Hemangioblastomas: Retrospective Series of 23 Cases. World Neurosurgery 103:248-256. 
doi:http://dx.doi.org/10.1016/j.wneu.2017.03.144

9. Takeuchi S, Tanaka R, Fujii Y, Abe H, Ito Y (2021) Surgical Treatment of Hemangioblastomas with Presurgical Endovascular Embolization. Neurol Med Chir 41:256-252

10. Medvedev YA, Matsko DE, Zubkov YN, Pak VA, Alexander LF (1991) Coexistent hemangiobalstoma and arteriovenous malformation of the cerebellum. Journal of Neurosurgery 75. doi: https://doi.org/10.3171/jns.1991.75.1.0121

11. Byun J, Yoo HJ, Kim JH, Kim YH, Cho YH, Hong SH, Kim CJ (2019) Growth rate and fate of untreated hemangioblastomas: clinical assessment of the experience of a single institution. Journal of Neuro-Oncology 144:147-154. doi:https://doi.org/10.1007/s11060-019-03213-z

\section{Figures}

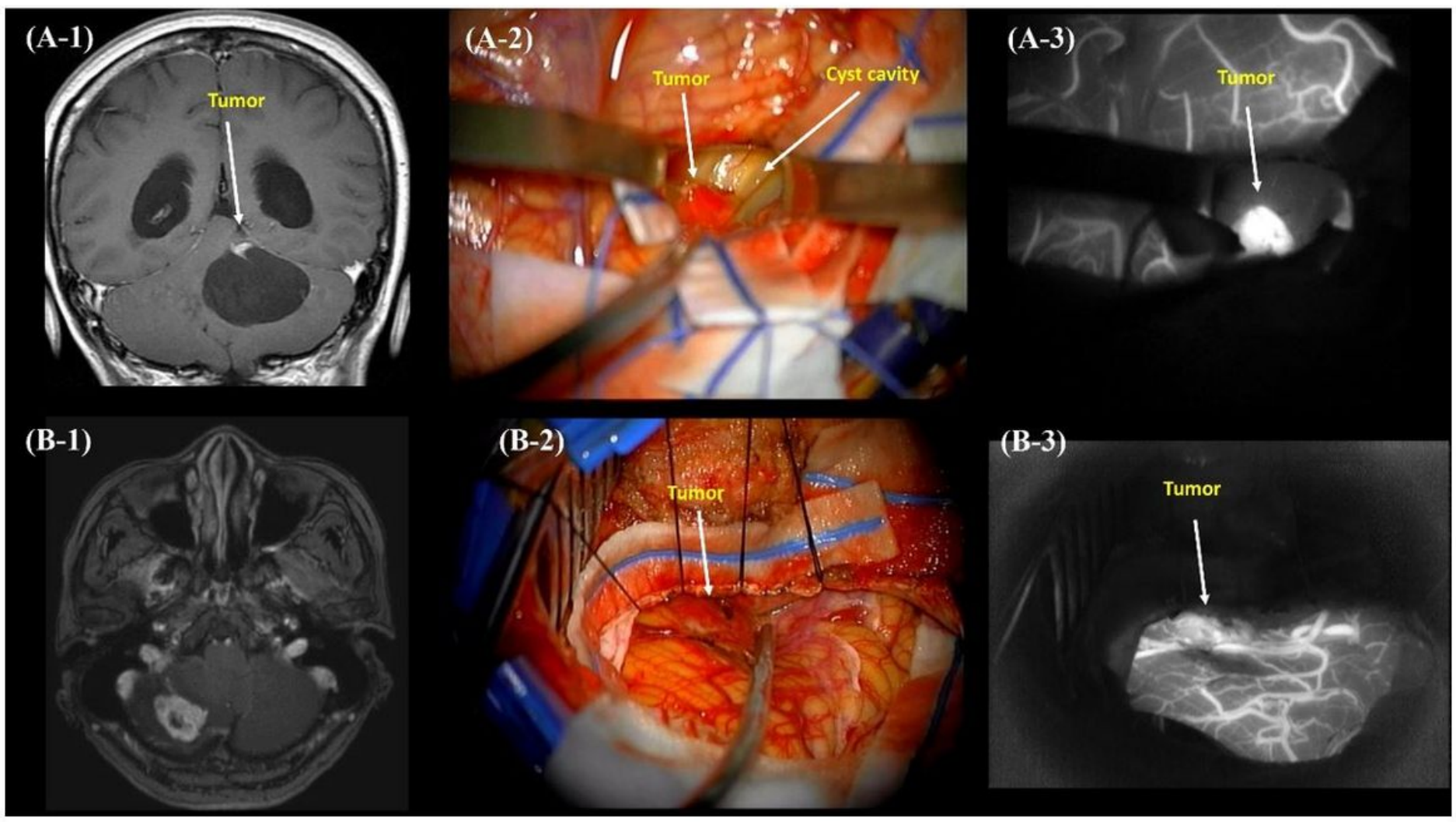

\section{Figure 1}

Application of indocyanine green angiography during hemangioblastoma surgery $(A-1,2,3)$ Radiologic and intraoperative findings of Case 1 as described in the Results section. (A-1) A small enhancing nodule was noted in the superior aspect inside of the tumor cyst in the right cerebellum. (A-2) Intraoperative photography. Slightly pinkish tissue was identified inside of the cyst. (A-3) Indocyanine green (ICG) videoangiography: ICG fluorescence uptake of the tumor was high. The tumor is shown as a bright vascular mass. It was resected totally. $(B-1,2,3)$ Radiologic and intraoperative findings of Case 2 as described in the Results section. (B-1) Well-enhanced solid tumor in the right cerebellar hemisphere on brain magnetic resonance imaging. (B-2) Intraoperative photography. The exact location of the subcortical tumor was hard to localize via gross inspection. (B-3) ICG videoangiography: The tumor was well visualized under ICG fluorescence microscopy mode because it was located just beneath the cerebellar cortex. In addition, feeding arteries of the tumor are shown. These should be coagulated first. 


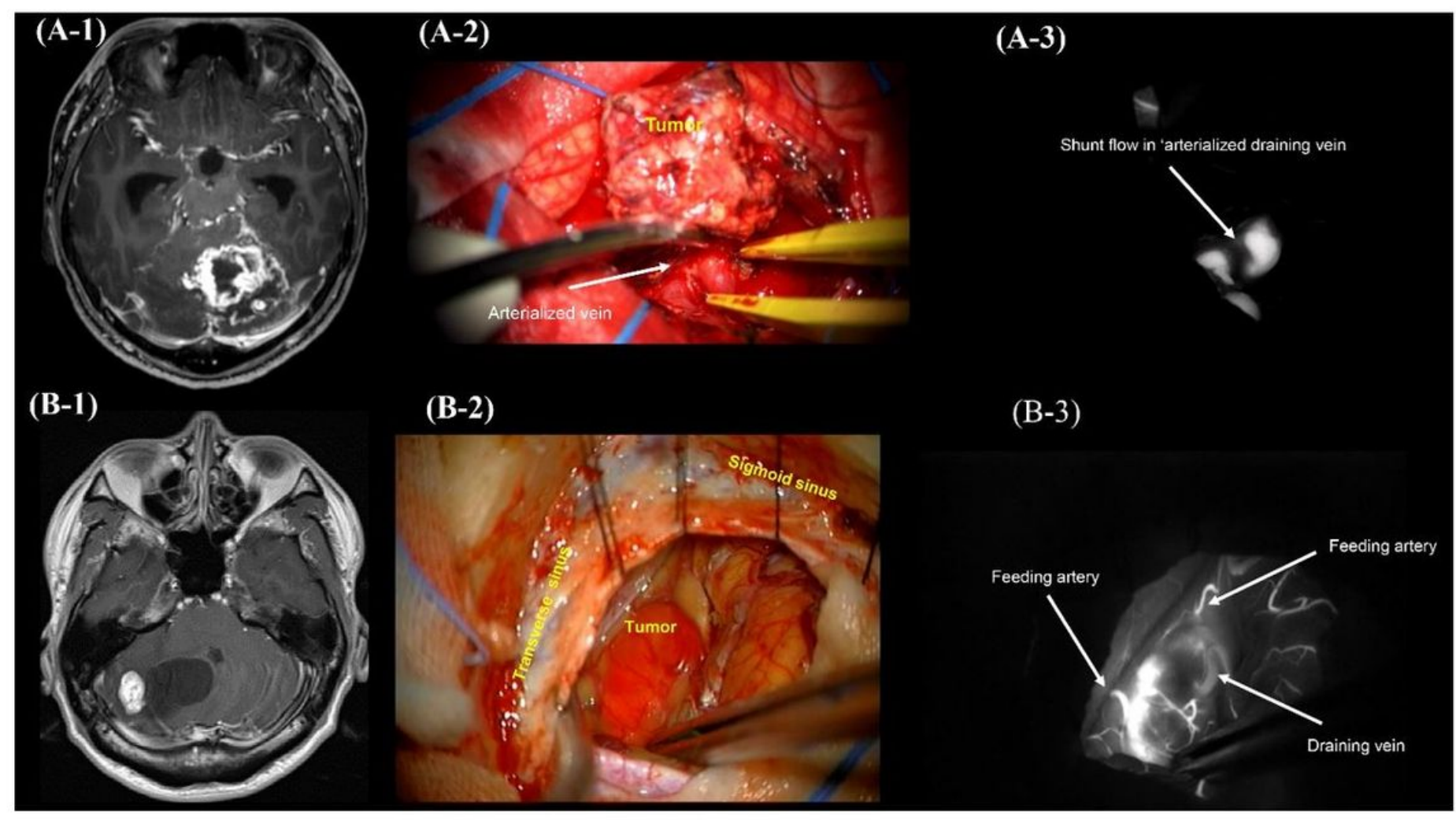

\section{Figure 2}

Application of indocyanine green angiography during hemangioblastoma surgery $(A-1,2,3)$ Radiologic and intraoperative findings of Case 3 as described in the Results section. (A-1) A large extremely hypervascular mass in the left cerebellar hemisphere and vermis. (A-2) Intraoperative photography. The solid tumor with an arterialized tumordraining vein that drained to the tentorial sinus. Shunt flow was evaluated using indocyanine green (ICG) angiography. The draining vein was ligated after coagulation of major feeders to prevent devastating bleeding from the drainage system. (A-3) High shunt flow was detected by ICG angiography and was helpful for determining the resection strategy during resection. (B-1,2,3) Radiologic and intraoperative findings of Case 4 as described in the Results section. (B-1) A solid tumor with a large cyst was noted in the right cerebellum. The patient denied blood transfusion because he was a Jehovah's witness. (B-2) The tumor was identified at the tentorial surface of the cerebellum. To minimize bleeding during surgery, identification of all feeding arteries and draining veins was necessary. (B-3) ICG angiography helped to identify feeding arteries and veins. Blood loss during the whole procedure was less than $100 \mathrm{~mL}$.

\section{Supplementary Files}

This is a list of supplementary files associated with this preprint. Click to download.

- Video2.mp4

- Video3.mp4

- Video1.wmv 